\title{
Energy System Planning Considering Renewables and Pumped-storage Power Plants
}

\author{
Jonas C. Costa, Student Member, IEEE, Edson C. Bortoni, Senior Member, IEEE, \\ Paulo A. V. Vieira, Student Member, IEEE, and Victor A. D. Faria, Student Member, IEEE
}

\begin{abstract}
Renewables will play an important role in the generation for the next decades, but the great problem they face is the intermittency of the natural resource availability, mainly when considering solar and wind generation. In this context, the pumped-storage finds a great opportunity. Its operation consists of two mains mechanisms: to pump water to be stored in an upper reservoir when there is surplus of energy in the system, and to generate as a regular power plant, with the stored water, when there is a lack of energy in the system. This paper presents an introductory with a revision of the world consumption and capacity of 2030 considering the parcel of renewables, and a simulation of several possibilities of the energy mix in various Scenarios. The simulations consider mainly the contribution of pumped-storage hydro. The possible arrangements of construction pumped-storage hydro, costs, and a mathematical model of linear optimization using pumped-storage are analyzed and presented. The developed method is applied to several Scenarios and the conclusions are obtained from that.
\end{abstract}

Index Terms - System planning, pumped-storage, renewable energy.

\section{INTRODUCTION}

$\mathrm{I}$ possible future scenarios, renewable generation will become more important and will have a big share in the generation mix, helping to reduce the emissions caused by coal and gas generation and to reduce the amount of $\mathrm{CO}_{2}$ in the atmosphere. Therefore, renewable use seems to be a non-return path. Table I shows the world mix and the installed capacity, for some years ago and expected for 2030 [1].

The greatest problem of renewable generation is the intermittency. Even in the hydro based power generation there is intermittency. The flow of water's regime is not constant, and in the past, reservoirs were built to regulate the flow.

The same idea is used nowadays for all scales of power generation and electrical and non-electrical batteries of different magnitudes have been used to regulate the intermittency of renewable resources [2-4], and generating when there is an energy deficit.

Manuscript received September 11, 2017; revised September 29, and October 9, 2017; accepted November 20, 2017.

Jonas C. Costa is with the Energy Research Enterprise, Rio de Janeiro, RJ, 20090-003 Brazil (e-mail: jonas.costa@epe.gov.br).

E. C. Bortoni, Paulo A. Vieira, and Victor A. D. Faria are with the Itajubá Federal University, Itajubá, MG 37500-903 Brazil (e-mail: bortoni@unifei. edu.br, pauloviana@unifei.edu.br,duraes_victor@unifei.edu.br).
TABLE I. WORLD CONSUMPTION AND CAPACITY OF ELECTRICITY [4].

\begin{tabular}{|c|c|c|c|c|c|c|c|c|}
\hline & \multicolumn{4}{|c|}{ Electricity generation (TWh) } & \multicolumn{2}{|c|}{ Growth $(\% \mathbf{p a})$} & \multicolumn{2}{|c|}{ Change vs. RS $(\%)$} \\
\hline & 1990 & 2004 & 2015 & 2030 & $\begin{array}{r}2004 \\
2015\end{array}$ & $\begin{array}{r}2004- \\
2030\end{array}$ & 2015 & 2030 \\
\hline Total generation & 11731 & 17408 & 23682 & 29835 & 2.8 & 2.1 & -4.6 & -11.6 \\
\hline & 4478 & 6917 & 9751 & 10914 & 3.2 & 1.8 & -8.1 & -25.8 \\
\hline Oil & 1313 & 1161 & 1154 & 869 & -0.1 & -1.1 & -3.4 & -7.6 \\
\hline$G_{25}$ & 1613 & 3412 & 4730 & 6170 & 3.0 & 2.3 & -9.6 & -20.8 \\
\hline Nuclear & 2013 & 2740 & 3268 & 4106 & 1.6 & 1.6 & 5.1 & 24.3 \\
\hline Hydro & 2148 & 2809 & 3738 & 4903 & 2.6 & 2.2 & 1.5 & 3.2 \\
\hline Renewables (excluding hydro) & 166 & 369 & 1041 & 2872 & 9.9 & 8.2 & 5.5 & 26.8 \\
\hline Biomiss and waste & 125 & 227 & 455 & 983 & 6.5 & 5.8 & 8.0 & 22.2 \\
\hline Wind & 4 & 82 & 449 & 1440 & 16.7 & 11.6 & 3.8 & 273 \\
\hline Geothermal & 36 & 56 & 100 & 185 & 5.5 & 4.7 & 0.3 & 6.3 \\
\hline Solar & 1 & 4 & 34 & 238 & 21.0 & 16.8 & 12.8 & 67.8 \\
\hline Tide and wave & 1 & 1 & 2 & 25 & 11.3 & 15.8 & 243 & 117.2 \\
\hline
\end{tabular}

\begin{tabular}{|c|c|c|c|c|c|c|c|}
\hline & \multicolumn{3}{|c|}{ Capacity (GW) } & \multicolumn{2}{|c|}{ Growth $(\% \mathbf{p a})$} & \multicolumn{2}{|c|}{ Change vs. RS (\%) } \\
\hline & 2004 & 2015 & 2030 & $\begin{array}{r}2004 \\
2015 \\
\end{array}$ & $\begin{array}{r}2004- \\
2030 \\
\end{array}$ & 2015 & 2030 \\
\hline Total capacity & 4054 & 5418 & 7104 & 2.7 & 2.2 & -4.1 & -9.8 \\
\hline & 1235 & 1664 & 1885 & 2.7 & 1.6 & -8.9 & -26.5 \\
\hline Oil & 453 & 466 & 336 & 0.3 & -1.1 & -3.0 & -11.2 \\
\hline Gas & 1055 & 1491 & 2059 & 3.2 & 2.6 & -7.0 & -16.6 \\
\hline Nucleas & 364 & 412 & 519 & 1.1 & 1.4 & 5.3 & 24.7 \\
\hline Hydro & 851 & 1100 & 1431 & 2.4 & 2.0 & 1.9 & 4.2 \\
\hline of which promped stonges & 79 & 79 & 79 & 0.0 & 0.0 & - & - \\
\hline Renewables (excluding hydro) & 96 & 285 & 874 & 10.4 & 8.9 & 5.3 & 29.6 \\
\hline Biomess and waste & 36 & 74 & 158 & 6.7 & 5.8 & 79 & 22.0 \\
\hline Wind & 48 & 174 & 538 & 12.5 & 9.8 & 3.7 & 25.3 \\
\hline Geothermal & 8 & 15 & 26 & 5.4 & 4.6 & 0.3 & 6.0 \\
\hline Solar & 4 & 22 & 145 & 17.7 & 15.2 & 12.9 & 65.6 \\
\hline Tide and wave & 0 & 0 & 7 & 6.0 & 13.3 & 23.7 & 116.9 \\
\hline
\end{tabular}

The pumped-storage plant (PSP) plays a very special role in a power system full of renewables, storing excess energy. In fact, there is a great intermittence in the energy input. Solar and wind varies a lot depending on environmental issues. Therefore, the PSP sends water to an upper reservoir, storing energy when its price is low, and acts as a conventional hydro power plant generating energy at a higher price, balancing the system and making it a profitable resource for the system operation [5].

This paper presents the role of pumped hydro, mainly for its characteristics of storing a great amount of energy. The basics of pumped hydro is presented, their cost, and a mathematical model of linear optimization is presented in order to simulate the energy mix in the fore coming years.

\section{Pumped Storage Basics}

Storage is considered the essential partner to wind and solar generation, making renewable power dispatchable, reliable, and efficient, spreading its application to a wide coverage. What is new is not the idea of storage, but the need for a different magnitude of it to accommodate an intermittent power supply in order to balance the energy over a cycle of storage and generation.

PSP have an upper water reservoir, which can be either natural or artificially created, and a lower reservoir that can be a lower basin or a river. In case electricity is required, water 
flows from top to bottom, driving a turbine-generator set, and electricity is delivered through a transformer to the grid. In case of electricity in excess, motor drives a pump which sends the water from the lower reservoir to the upper reservoir and potential energy is stored [5].

In the pump mode the electric machine act as a motor and the speed of the unit is varied in accordance to the amount of water wanted to be stored per time. When the power plant acts as a conventional hydro power plant, the electrical machine works as a generator connected through a compatible element to a fixed frequency grid.

PSP can also have an upper reservoir with a natural input; therefore hydro is renewable power generation and energy storage in one plant. Depending on stored volume the pumped hydro can be classified among daily, weekly, monthly and yearly regulation.

The basic equation of the generated power is

$$
P=\rho g Q \Delta h \eta
$$

Where $P$ is the generated power $(\mathrm{kW}), \rho$ is the water density $\left(\mathrm{kg} / \mathrm{m}^{3}\right), g$ is the local gravity constant $\left(\mathrm{m} / \mathrm{s}^{2}\right), Q$ is the water flow $\left(\mathrm{m}^{3} / \mathrm{s}\right), \Delta h$ is the height difference, and $\eta$ is the overall efficiency of power conversion (p.u).

The available consolidate technologies of bulk energy storage that are suitable for the operation with and integration of large scale new renewables are the compressed air storage and the pumped storage. PSP exists in some different arrangement sets of machines: binary reversible machine sets, (pump-turbine motor-generator); ternary systems (consist of separate hydraulic machines installed on the same axis of the motor-generator); or even quaternary systems (in which the pump-motor set is completely separated from the turbinegenerator set).

One of the state-of-art arrays is the ternary system, it consists of a motor-generator and separates turbine (typically Francis or Pelton) from the pump set. As two separate hydraulic machines, the rotation direction of the motor-generator can be the same while pumping or generating energy, reducing the mechanical stress on the axis and the unit can change from one mode to other more often, up to 200 times in a day. For the switching between turbine and pump operation, a clutch operable at standstill, a starting turbine or a synchronizing torque converter can be used. A scheme of this array is showed in Fig. 1.

Other concept of array for a pumped storage scheme that is largely installed is the binary system and consists of a motorgenerator and a reversible pump-turbine that works either as pump-motor or as a turbine-generator depending on the direction of rotation, this scheme can be seen in Fig. 2. With a wide range of specific speeds, pump-turbines can be installed at sites with heads from less than 50 to more than $800 \mathrm{~m}$, and with unit capacities ranging from less than 10 to over $500 \mathrm{MW}$.

If the system is assebled using an asynchronous motorgenerator the rotational speed of the pump turbine can be varied, thus, the pump capacity can be adjusted to use the currently available amount of energy, which allows the project of more compact power houses, implying in savings on equipment and civil costs.
Pump storage is localized in the system as bulk storage, often near generation on the grid.

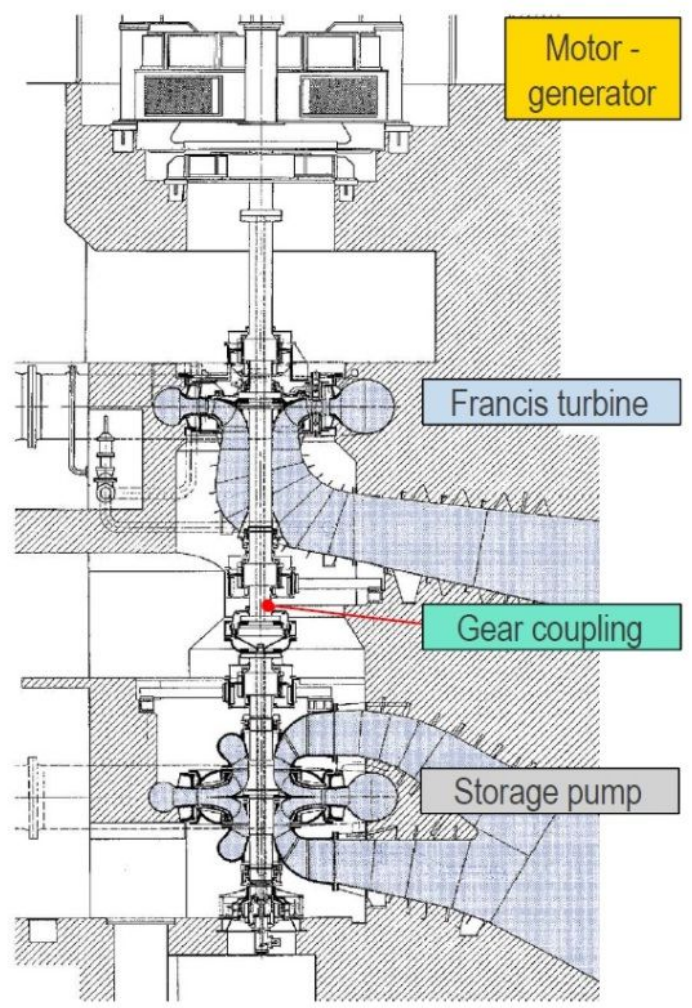

Fig. 1. Ternary group of Salto del Pintado PSP [6].

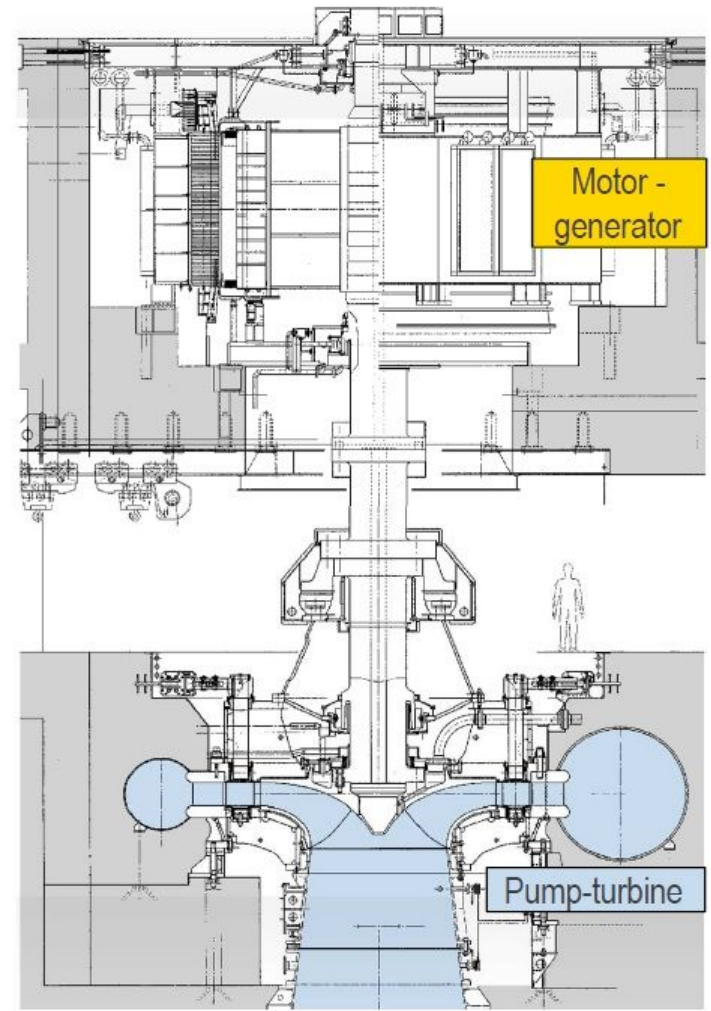

Fig. 2. Binary group of Goldisthal PSP [6]. 
This design allows for more compact power houses implying in savings on equipment and civil costs. Pump Storage is located in the system as bulk storage, often near generation on the grid.

\section{Methodology}

It was considered that in an ideal electric system all the generated energy must be consumed instantly, or that each instantaneous demand for electric energy must have an equivalent instantaneous generation, once the system is not provided with ancillary services of batteries and the losses in transmission lines are not considered. The utilized mix of sources to provide power for the electric load consists of nuclear plants, hydro power, coal, gas peaking, wind farms and solar farms. The equations below show the approach adopted to solve the optimized dispatch problem.

$$
\begin{aligned}
& P_{t}=D_{t} \\
& P_{t}=\sum_{\substack{i \in I \\
t=T}} p_{i t}
\end{aligned}
$$

Where $P_{t}$ is generated power in instant of time $t$, pit is the generated power by each considered source at instant of time $t$. $I$ is the set of power sources, i.e., nuclear, hydro, coal, gas peaking, wind, and solar; and $T$ is the set of time intervals.

The best solution to meet the demand is related to the mix of generation sources that gives the lowest energy price, taking into account the availability and the variable price in US\$/MWh of each power supply that can be dispatched. In order to achieve the minimum cost of operation for the system, an optimization problem was solved using linear programming. The method consists in achieving the lowest cost to attend demand, mixing the different sources of power. The balance is made considering different prices for the available sources: nuclear, coal, gas peaking, hydro, wind and solar. The objective function of the optimization is shown above; its parameters were subjected to linear equalities and linear inequalities constraints.

$$
D_{t}=\sum_{\substack{i \in I \\ t \in T}} x_{i} p_{i t}
$$

One of the simulation's objective was to test if a pumped storage can maximize the share of new renewables, wind and solar, as this source compete with the other sources. This would avoid wind and solar generation curtailments in periods of low demand, and minimize the dispatch of coal and nuclear plants as well as the run of gas peaking machines.

TABLE II. LEVELIZED COSTS OF ENERGY [6]

\begin{tabular}{lccc}
\hline \hline \multirow{2}{*}{ Power Source } & \multicolumn{3}{c}{ US\$/MWh } \\
\cline { 2 - 4 } & Min & Max & Average \\
\hline Solar utility scale & 49 & 61 & 55 \\
\hline Solar rooftop & 78 & 135 & 106.5 \\
\hline Wind onshore & 32 & 62 & 47 \\
\hline Wind offshore & 118 & 118 & 118 \\
\hline CSP & 119 & 182 & 150.5 \\
\hline Biomass & 77 & 110 & 93.5 \\
\hline
\end{tabular}

\begin{tabular}{lccc}
\hline Gas peaking & 165 & 217 & 191 \\
\hline Nuclear & 97 & 136 & 116.5 \\
\hline Coal & 60 & 143 & 101.5 \\
\hline Hydro & 40 & 77 & 58.5 \\
\hline Pumped Storage & 188 & 274 & 231 \\
\hline \hline
\end{tabular}

Once the inputs of the natural resources are made to estimate how much energy is available from new renewables, it is possible to estimate the renewable energy cut to scale out a bulk storage capacity to enhance the operation of the system.

\section{AdOPTED SCENARIOS}

The formulation was applied to three different mixes of sources called Scenarios 1, 2 and 3. Scenario 1 comprehends a hydro based system projected to the 2030 horizon. Scenario 2 is a thermo-based system projected to the 2027 horizon. Scenario 3 is an all renewables system planned to the 2050 horizon. The share of each source in the mix is scaled in installed power. The figures below show the electrical mix of sources for each given Scenario.

In the Scenario 1, the pitced in Fig. 3, the hydro power plants are considered run of river and therefore do not have storage capacity for regularization of the generation. The affluent natural energy is of a dry period, when the flow of water is $45 \%$ of the maximum of the average historical series of flows in ten years. It also takes in consideration a share of $16 \%$ of new renewables in the mix. The scenario 1 is shown in Fig. 3.

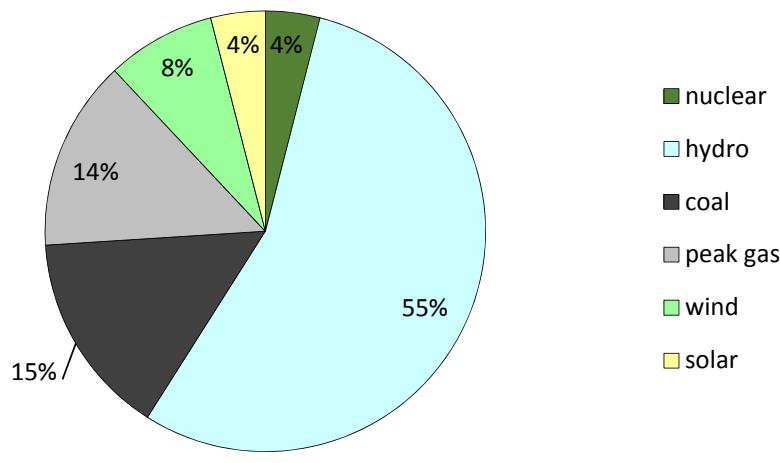

Fig. 3. Mix in a hydro-based PES.

In Scenario 2 it is proposed a change from a thermo-based energy mix of sources to a more renewable one, through the insertion of new renewables: wind and solar. These mixes were evaluated using the optimization model in order to achieve the best combination of sources. The price of energy for each source was set in according with the reference values in Table II and the best economically dispatch, in according with the simulation, indicates rather if there is lack or surplus of renewable energy, with the objective to increase the share of new renewables throughout the use of pumped storage. Such change on the mix can be observed comparing the Fig. 4 with the Fig. 5.

In the Scenario 3, depitched in Fig. 6, the mix power generation sources are solar photovoltaic, wind onshore, concentrated solar power and biomass. The total installed capacity accounts for $154 \mathrm{GW}$ and as its nature for 
intermittency, is natural to predict that energy storage shall be indispensable for the operation and meeting the load.

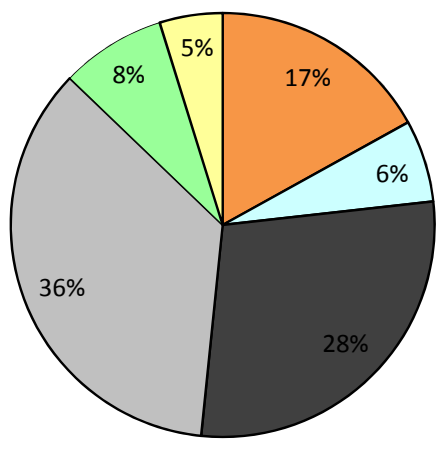

$\square$ nuclear
$\square$ hydro
$\square$ coal
$\square$ peak gas
$\square$ wind
$\square$ solar

Fig. 4. Mix in a thermo-based PES.

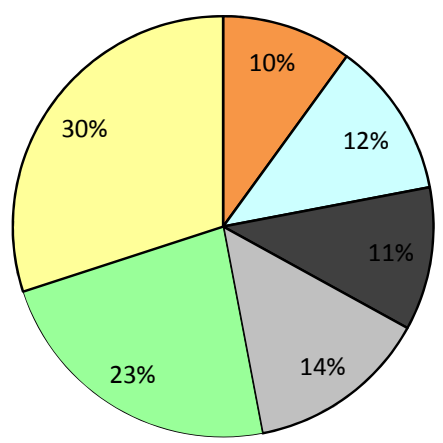

$\square$ nuclear

$\square$ hydro

$\square$ coal

$\square$ peak gas

$\square$ wind

$\square$ solar

Fig. 5. Mix in an all renewable PES.

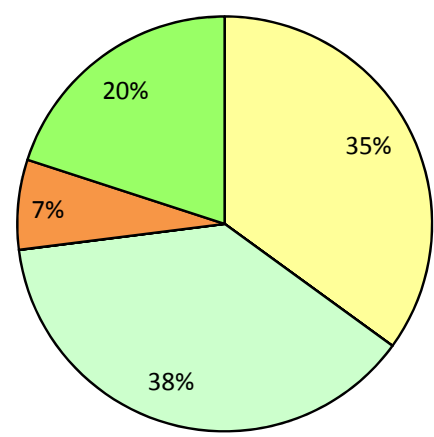

$\square$ solar

$\square$ wind

$\square$ CSP

$\square$ Biomass

Fig. 6. Mix in an all renewable PES

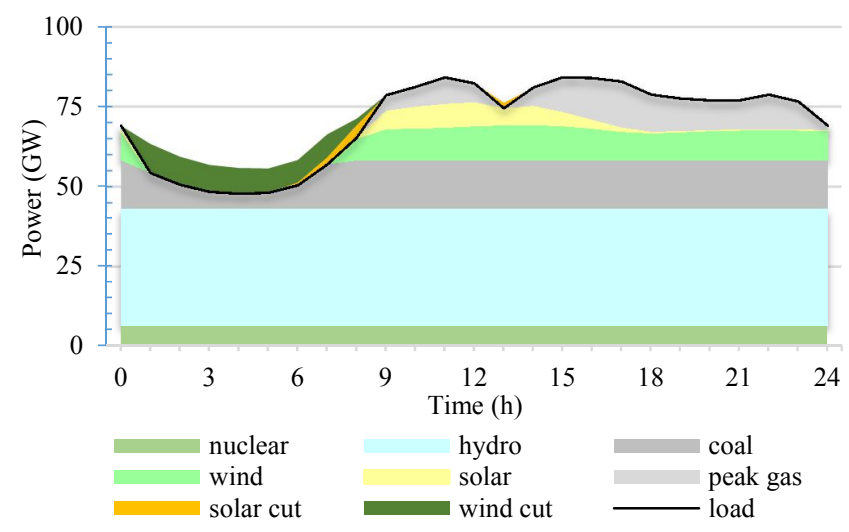

Fig. 6. Optimized dispatch for Scenario 1, mix of sources without PSP.
The end costs of energy per source used to ponder the level of usage of each installed capacity are shown in the Table III [6]; these values were extracted from the Lazard's report of December 2016.

\begin{tabular}{lcc}
\multicolumn{2}{c}{ TABLE III. PRICES CONSIDERED IN SCENARIO 1 } \\
\hline \hline Power Source & US \$MWh & Capacity Factor \\
\hline Nuclear & 97 & 0.95 \\
\hline Hydro & 40 & 0.60 \\
\hline Coal & 60 & 0.65 \\
\hline Wind & 62 & 0.60 \\
\hline Solar & 55 & 0.32 \\
\hline Gas peaking & 191 & 0.95 \\
\hline PSP & 188 & - \\
\hline \hline
\end{tabular}

The report brings a range of values from minimum to maximum real prices from different plants all over the United States. For the calculations, mainly the average value of each source was considered.

\section{Simulation AND RESUlts}

The results for the simulations of the given Scenarios above are shown on the frames below. The Figs. 6 and 7 presents the accomplishments for the Scenario 1. For that simulation the nuclear energy availability was considered inflexible due to operational characteristics of the system and the other sources are varying with the market prices of the energy for each one. With those given conditions, the optimum dispatch for the system results in a wind and solar energy cut in the period of lower demand.

If the PSP is introduced into the mix's mix of sources the renewable energy becomes useful, pumping water and storing potential energy for later use. During the peak hours the energy is re-leased into the power electric system and contributes to attend the peak demand, avoiding the dis-patch of expensive gas peaking, as it appears in Fig. 8, making use of clean energy and resulting on a lower operational cost in $\mathrm{U} \$ \mathrm{MWh}$, as appears in Table IV.

\begin{tabular}{lcc}
\multicolumn{4}{c}{ TABLE IV. RESUlts OF SCENARIO 1 } \\
\hline \hline Scenario 1 & Without PSP & With PSP \\
\hline Renewable energy cut $(\mathrm{GWh})$ & 59.9 & 2.9 \\
\hline Operation cost $(\mathrm{US} \$ \mathrm{MWh})$ & 70.3 & 65.4 \\
\hline Installed Capacity $(\mathrm{GW})$ & 136 & 141 \\
\hline \hline
\end{tabular}

In Scenario 2, if it is considered that the power sources are competing in the market and are dis-patched for their price from the lowest to the highest, the surplus of renewable energy is available only when there is the renewable resource available and the price operation of such a renewable power plant is higher than the price of thermal sources such as coal and gas. Fig. 9 presents the results of the linear optimization for the mix presented in Fig. 4. In this case wind energy is more expensive than coal energy, as shown in table. This must be considered that nuclear power plants are inflexible, the result is a wind power cut in the period of low demand. The prices considered in Scenario 2 are presented in Table V. Table VI presents the results of Scenario 2, nuclear inflexible.

On the other hand if the nuclear plants are flexible to vary with the market prices and if the wind energy is cheaper than 
coal energy, the optimization model results in the total absorption of renewable energy that is available in the system and no storage is needed to compensate and accumulate the surplus for further use, once the coal plants will run as a backup when the source is not available. The prices are the same and the results are presented in Table VII.

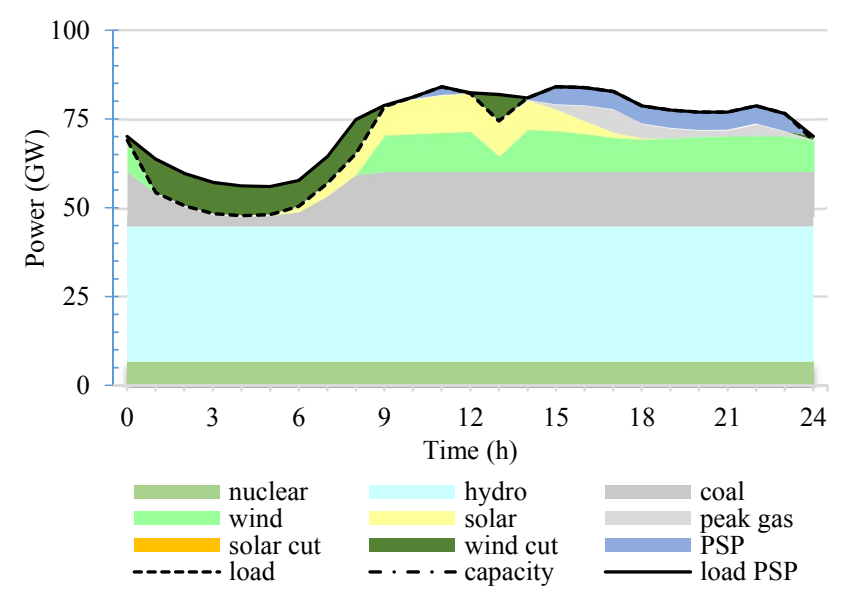

Fig. 7. Optimized dispatch for Scenario 1, mix of sources with PSP.

Considering an increase in renewables for the 2027 year, as shown in Fig. 5, the problem indicates the best dispatch to meet the load as in Fig. 10. In order to achieve this solution the thermal nuclear and coal plants were considered inflexible because of power security. This it is possible to maximize and scale up the pumped storage for bigger energy absorption during days when the natural affluent energy is plenty.

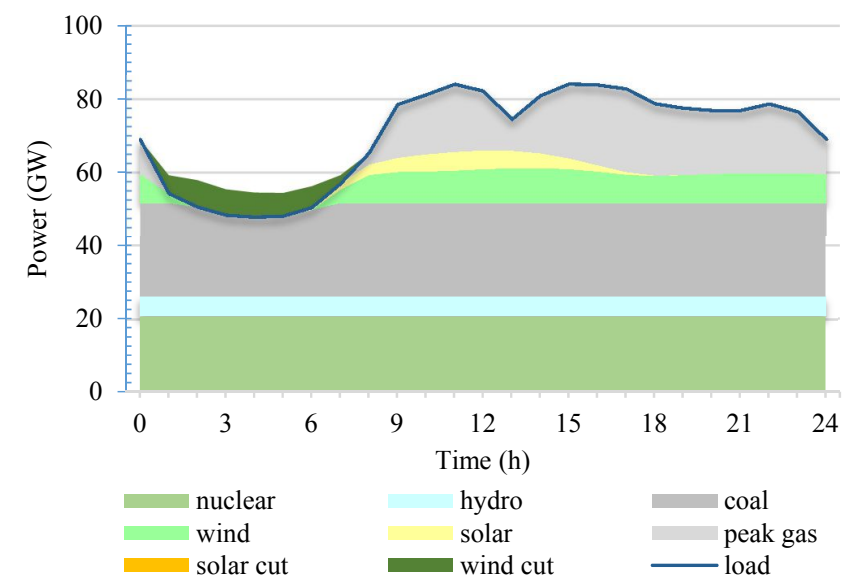

Fig. 8. Optimized dispatch for Scenario 2 with nuclear inflexibility.

TABLE V. PRICES CONSIDERED IN SCENARIO 2

\begin{tabular}{lcc}
\hline \hline Power Source & US\$/MWh & Capacity Factor \\
\hline Nuclear & 97 & 0.95 \\
\hline Hydro & 58.5 & 0.60 \\
\hline Coal & 60 & 0.65 \\
\hline Wind & 62 & 0.60 \\
\hline Solar & 49 & 0.32 \\
\hline Gas peaking & 191 & 0.95 \\
\hline PSP & - & - \\
\hline \hline
\end{tabular}

TABLE VI. RESULTS OF SCENARIO 2 - NUCLEAR INFLEXIBLE

\begin{tabular}{ll}
\hline \hline Scenario 2 & Without PSP \\
\hline Renewable energy cut $(\mathrm{GWh})$ & 43.6 \\
\hline Operation cost $(\mathrm{US} \$ \mathrm{MWh})$ & 90.0 \\
\hline Installed capacity $(\mathrm{GW})$ & 136 \\
\hline \hline
\end{tabular}

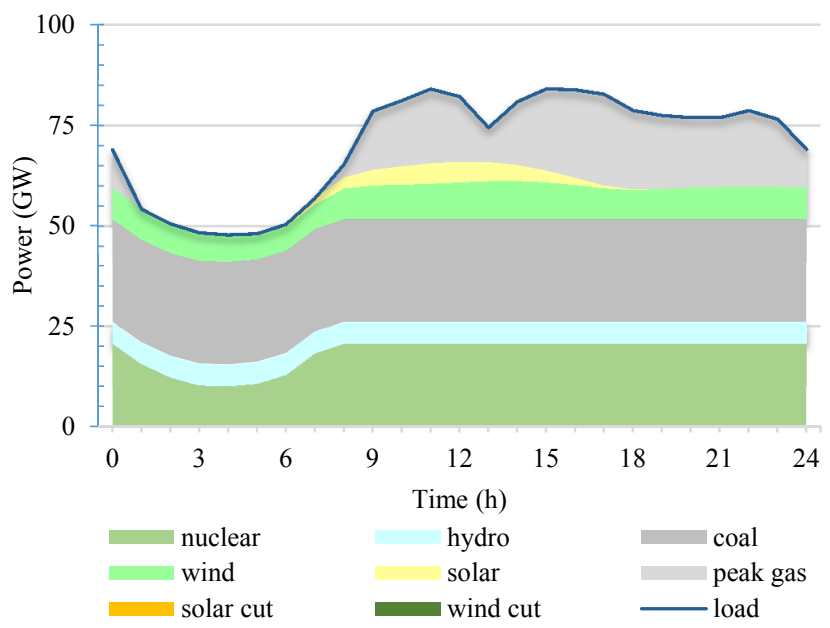

Fig. 10. Optimized dispatch for Scenario 2 with nuclear flexibility.

The share of each source in the mix is scaled in installed power. The following figures show the mix for each given Scenario. Figure 12 shows the optimized dispatch for Scenario 2 with increase of renewables running on nuclear and coal inflexibility and with PSP. The problem solving was applied to three different source mix named as Scenarios 1, 2 and 3. Scenario 1 comprehends a hydro based system projected to the 2030 horizon. Scenario 2 is a thermo-based system projected to the 2027 horizon. Scenario 3 is an all renewables system planned to the 2050 horizon.

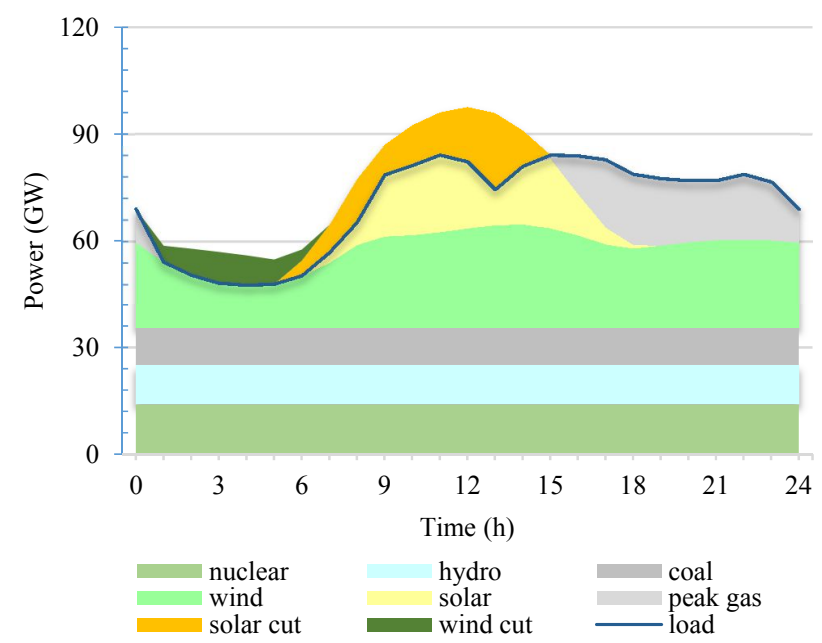

Fig. 11. Optimized dispatch for Scenario 2 with increase of renewables running on nuclear and coal inflexibility.

The model also considered energy storage using PSP. Table VIII shows the considered proces for nuclear flexible. While Table IX presents the main results obtained for Scenario 2 
considering nuclear generation inflexible. In the all renewable Scenario, there is surplus of energy during the first hours of the day, including the period when the demand is highest. In the least hours of the day the generation coming from the available sources do not have enough installed capacity to meet the electric load, as it is shown in Fig. 13.

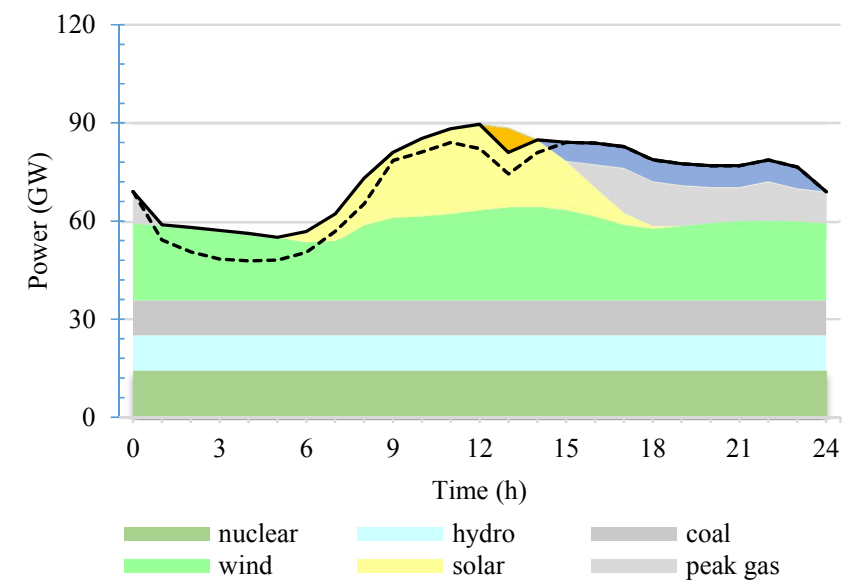

Fig. 12. Optimized dispatch for Scenario 2 with increase of renewables running on nuclear and coal inflexibility and with PSP.

TABLE VII - RESULTS IN SCENARIO 2 - NUCLEAR FLEXIBLE

\begin{tabular}{lc}
\hline \hline Scenario 2 & Without PSP \\
\hline Renewable energy cut $(\mathrm{GWh})$ & 0.0 \\
\hline Operation cost $(\mathrm{US} \$ \mathrm{MWh})$ & 88.5 \\
\hline Installed capacity $(\mathrm{GW})$ & 136
\end{tabular}

TABLE VIII. PRICES CONSIDERED IN SCENARIO 2

\begin{tabular}{lcc}
\hline \hline Power Source & US $\$$ MWh & Capacity Factor \\
\hline Nuclear & 97 & 0.95 \\
\hline Hydro & 40 & 0.60 \\
\hline Coal & 60 & 0.65 \\
\hline Wind & 32 & 0.60 \\
\hline Solar & 49 & 0.32 \\
\hline Gas peaking & 191 & 0.95 \\
\hline PSP & 188 & - \\
\hline \hline
\end{tabular}

TABLE IX. RESULTS OF SCENARIO 2 - NUCLEAR INFLEXIBLE

\begin{tabular}{lcc}
\hline \hline Scenario 2 & Without PSP & With PSP \\
\hline Renewable energy cut $(\mathrm{GWh})$ & 89.5 & 3.75 \\
\hline Operation cost $(\mathrm{US} \$ \mathrm{MWh})$ & 66.1 & 64.9 \\
\hline Installed capacity $(\mathrm{GW})$ & 150 & 156.5 \\
\hline \hline
\end{tabular}

TABLE X. PRICES CONSIDERED IN SCENARIO 3

\begin{tabular}{lcc}
\hline \hline Power Source & US $\$$ MWh & Capacity Factor \\
\hline CSP & 119 & 0.50 \\
\hline Biomass & 77 & 0.80 \\
\hline Wind & 32 & 0.60 \\
\hline Solar & 49 & 0.32 \\
\hline Gas peaking & 191 & 0.95 \\
\hline PSP & 188 & - \\
\hline \hline
\end{tabular}

When the system operates with storage capacity the extra amount of energy can be stored as water's potential energy. A fraction of this energy is lost due to the plant's machines performance. The efficiency adopted for the overall losses in the system, including the processes of pumping and generating was 0.87 . The prices and simulation results for Scenario 3 are presented in Tables $\mathrm{X}$ and $\mathrm{XI}$ respectively.

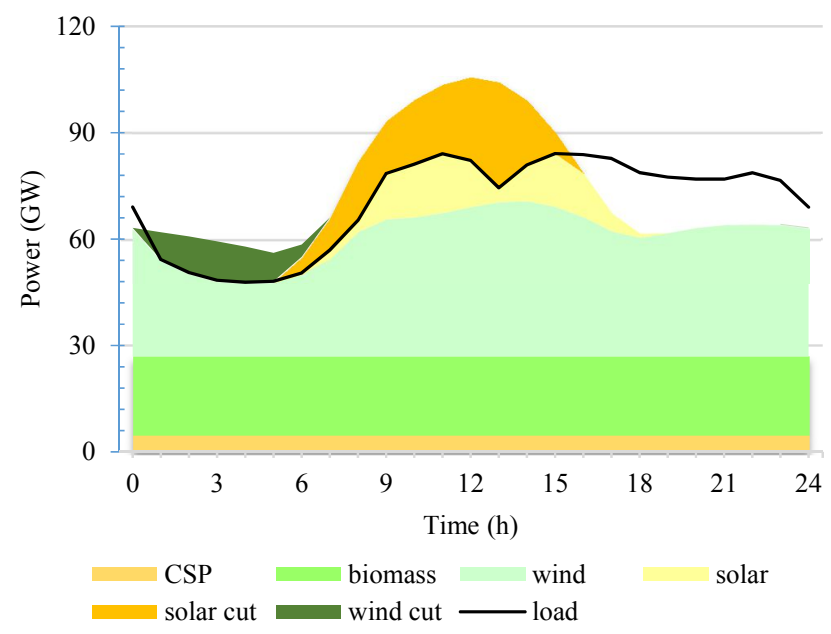

Fig. 13. Optimized dispatch for the all-renewable PES without storage system

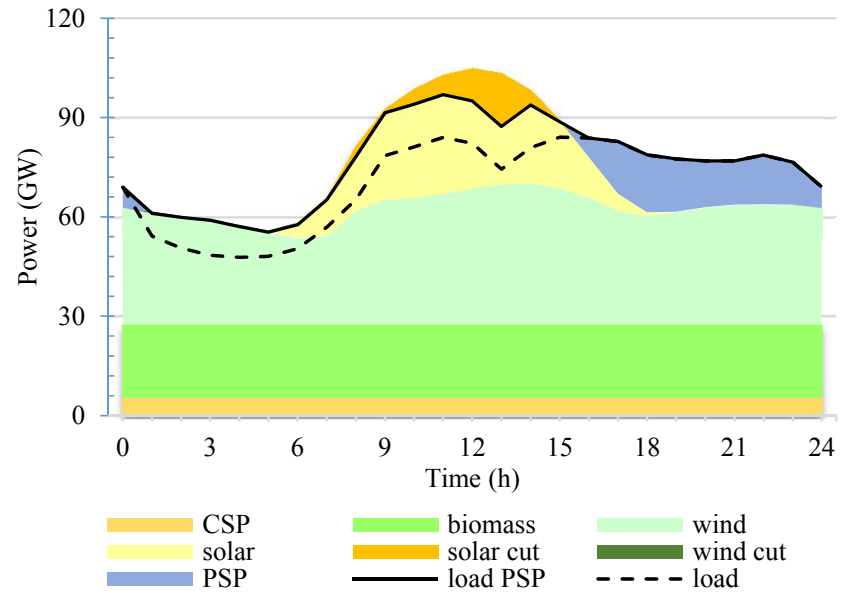

Fig. 14. Optimized dispatch for the all-renewable PES operating with a PSP

TABLE XI. RESULTS OF SCENARIO 3

\begin{tabular}{lcc}
\hline \hline Scenario 3 & Without PSP & With PSP \\
\hline Renewable energy cut $(\mathrm{GWh})$ & 190.7 & 27.5 \\
\hline Operation cost $(\mathrm{US} \$ \mathrm{MWh})$ & $63.0^{*}$ & 60.3 \\
\hline Installed capacity $(\mathrm{GW})$ & 154 & 154 \\
\hline \hline
\end{tabular}

As can be seen in Fig. 14, the installed capacity of PSP meets the demand in the least hours of the day using the extra energy from the first hours of the day. This is like saving sun and wind for later hours, when those resources are not fully available for the operation.

\section{CONCLUSIONS}

The purpose of the simulations was to test if the insertion of a PSP in the power electric system could result in operational gains for an optimal dispatch of the available sources in the system. The model was fed with data of two typical power systems in Scenarios 1 and 2, and with a possible future system data of only renewables, for Scenario 3. 
It was observed in all the simulations that the average operational cost of the systems decreased in US\$/MWh when there was renewable energy replacing coal and nuclear plants and decreased even more when there was a PSP storing cheap off-peak energy, often renewable energy, for peak use, replacing gas.

The base for the cheaper cost of operation provided by Lazard's indicate the price for the energy generated on renewable plants are getting cheaper and cheaper every year and becoming more attractive than nuclear, coal and gas. Another reason for the cheaper price is due to the system operating with a pumped storage system, the basic rule of profit: buying cheap and selling more expensive. It takes the power system to an economic better point of operation, even more when the pumped energy comes from renewables, for example, because they do not pay the fuel to run.

Comparing the gain caused by the PSP operation into the developed Scenarios is possible to quantify that in Scenario 1 the operation is $7 \%$ cheaper with PSP when accumulating extra wind energy. In Scenario 2, analyzing the increase on renewables, the cost of operation is $2 \%$ less with PSP than without, and in Scenario 3 besides being 4.3\% cheaper to operate the system with PSP, the storage use is mandatory in order to achieve the load demand on an all-renewable sources mix. When developing this work it was observed that other benefits that pumped storage can bring to the system operation as a provider of ancillary services were not considered.

Further development is possible to be made to quantify the overnight costs of implementation for these structures and to calculate the total economic viability using monetary mechanisms, like green bonds for not generating from $\mathrm{CO} 2$ emitter sources and avoided costs of fuel to run thermal plants once renewables run on free fuel.

This work showed a bit of what is already written in literature and of what is becoming reality in some parts of the world: batteries play an indispensable role in the change from operating the electric generation with carbon based sources to a more or total renewable based sources system. Accomplishing the goal of going renewable is really very feasible, once the technologies needed are all available in the market.

Finally, since techniques make it possible to be installed and is supposed to exist free market competition beyond the sources, two of the most important attitudes to be taken in order to achieve renewable and clean energy goals are the policy making and the programs of implementation.

\section{ACKNOWLEDGMENTS}

The authors would lie to thank FAPEMIG, CAPES, and $\mathrm{CNPq}$ for the continued support in conducting research.

\section{REFERENCES}

[1] S. David Freeman and Leah Y Parks, All-Electric America: A Climate Solution and the Hopeful Future, January 2016, ISBN 978-0-9961747-25.

[2] P.F. Ribeiro, B.K. Johnson, M.L. Crow, A. Arsoy, Y. Liu, Energy storage systems for advanced power applications. Proceedings of the IEEE, Vol 89(12), 2001, pp. 1744-1756.
[3] G. Carpinelli, G. Celli, S. Mocci, F. Mottola, F. Pilo, D. aniela Proto, Optimal Integration of Distributed Energy Storage Devices in Smart Grids. IEEE Transactions on Smart Grid, Vol. 4(2), 2013, pp. 985-999.

[4] Y.F.F.C. Silva, E.C. Bortoni, Electrical energy storage systems in smart grids: characteristics, opportunities and barriers. Brazilian Energy Review, Vol. 22(2), Mar. 2016, pp. 48-72.

[5] Z. Souza, A.H.M. Santos, E.C. Bortoni, Hydro power plants - Design and Commissioning. Novo Mundo Ed., 2009, 287 p.

[6] Voith website, Service and Products session, Pumped Storage topic. Last visit in October $9^{\text {th }}$ of 2017. http://www.voith.com/en/productsservices/hydro-power/pumped-storage-plants-551.html

[7] Lazard's Levelized cost of Energy Analysis - Version 10.0, December 2016.

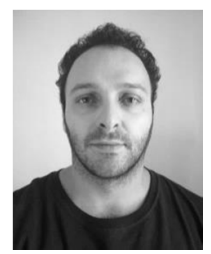

Jonas Carvalheira Costa was born in Maria da Fé, Brazil, on September 19, 1985. Jonas is an Electrical Engineer graduated at the Federal University of Itajuba, where he is currently working tword his Master Degree in the Energy Engineering Program. Most of his work experience is based on transmission lines planning in EPE (Energy Research Company) for the energy transport in the Brazilian power system. His interests inclues the planning of power generation, renewable sources, the challenges of energy storage, and smartr grids. Mr. Costa is a member of CIGRÉ.

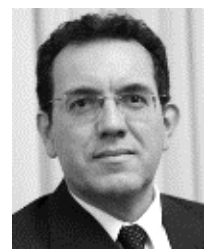

Edson da Costa Bortoni (S'94-M'96-SM'05) was born in Maringá, Brazil, on December 1, 1966. He received the degree in Electrical Engineering from Itajubá Federal University (UNIFEI), Itajubá, Brazil, in 1990; the M.Sc. degree in energy systems planning from the University of Campinas, Campinas, Brazil, in 1993; the D.Sc. degree in power systems from the Polytechnic School of the University of São Paulo (USP), São Paulo, Brazil, in 1998; and the Academic Scholar degree (Habilitation) from USP, São Carlos, Brazil, in 2012. He was a Visiting Professor at Amazon University, Manaus, Brazil, and Adjunct Professor at São Paulo State University, Guaratinguetá, Brazil, and a Visiting Scholar at École Polytechnique Fédérale de Lausanne, Switzerland. He is currently a Professor at UNIFEI. Dr. Bortoni is a member of the Editorial Committee of the IET Generation, Transmission and Distribution, and of the Flow Measurement and Instrumentation Journals. His research interests include electrical machines, instrumentation, power generation, smart grids, and energy systems. Dr. Bortoni is a Senior Member of the Institute of Electrical and Electronic Engineers, is a Senior Member of the International Society for Optical and Photonics, and a Fellow Member of the Instrument Society of Automation and of the Energy Efficiency Excellence Center.

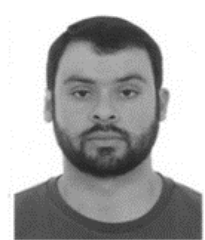

Paulo Alberto Viana Vieira was born in Itabira, Brazil, on April 16, 1987. In 2007 and 2008 he concluded technician school in electrical maintenance at Senai, and the technical course in electronics at the Technical College Itabirano-FIDE. He received a degree in Electrical Engineering from the Federal University of Itajubá (UNIFEI), Itabira, Brazil, in 2015. He received a CAPES Scholarship in the Sciences without Borders program, studying electrical engineering at the University of Texas at El Paso in the USA (2nd/2014 and $1 \% / 2015$ ). Paulo did an internship at University of Florida, Gainesville, Florida. He worked as a Protection and Control Engineer at JCV Energia and is currently a M.Sc. student Energy Systems Planning at UNIFEI. $\mathrm{He}$ is a member of the Center for Excellence in Energy Efficiency (EXCEN). His research interests include smart grids, energy storage, distributed generation, energy efficiency and power system protection.

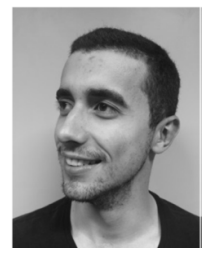

Victor Augusto Durães de Faria was born in Belo Horizonte, Brazil, on January 2, 1995. Victor is an undergraduate student in Electrical Engineering at the Federal University of Itajubá, Itajubá, Brazil. Victor did an internship at Michigan State University, Ann Arbor, Michigan. He has experience in optimization, planning, and modeling of electric power systems, techniques related to benefits apportionment in cooperative actions, modeling of synchronous machines, and identification of machines parameters. Currently, he is with the Centre of Excellence on Energy Efficiency at UNIFEI. His research interests include optimization, energy systems, electrical machines. 